\title{
Gewinnung und Reinigung von Adenovirus-Typ 2 mit Hilfe der CsCl-Gradientenzentrifugation
}

\author{
Von Kurt Köhler
}

\author{
Aus dem Max-Planck-Institut für Virusforschung, Tübingen \\ (Z. Naturforschg. 17 b, 544-547 [1962] ; eingegangen am 18. April 1962)
}

\begin{abstract}
Adenovirus Type 2 was grown on HeLa cells and purified by CsCl-gradient centrifugation. Three regions of bands were obtained, differing by their sedimentation rate and density in CsCl solutions. Electron microscopic investigations of negatively stained preparations show icosahedral particles with 252 subunits for the main virus region. The lighter bands consist of empty shells. A plaque test suiting the conditions was developed.
\end{abstract}

Die Viren der systematischen Gruppe der „Adenoviren“ 1 , zu denen außer den eigentlichen Adenovirus-Typen auch die Viren der Hunde-Hepatitis ${ }^{2}$, ein Maus-Adenovirus ${ }^{3}$, das GAL-Virus ${ }^{4}$ (GallusAdeno-Like, Avian Orphan Virus) u. a. gehören, sind durch ihre Struktur, ihre chemische Zusammensetzung und ihre Größe charakterisiert. Eine Hülle (Capsid) aus 252 Untereinheiten (Capsomeren) umgibt in der Form eines Icosaeders ${ }^{5}$ die Nucleinsäurekomponente, wahrscheinlich wohl einen zentralen Nucleoprotein-,,Kern“" ${ }^{6}$. Aus dem Vorkommen Feulgen-positiver Einschlußkörper ${ }^{7}$ sowie aus der Zunahme des DNS-Gehaltes der Zelle nach der Infektion ${ }^{8}$ wird wahrscheinlich, daß die Nucleinsäure im Adenovirus als DNS vorliegt. Der Nucleinsäure„Kern“ kann bei $p_{\mathrm{H}}$ 9,0 mit DNase herausgelöst werden. RNase ist im gleichen Versuch und unter anderen Bedingungen ohne Wirkung ${ }^{6}$. Außer Viruspartikeln produzieren Adenoviren - je nach Virustyp und Zellstamm - einige Antigene, ein Toxin und 2 komplementbindende Antigene (eines davon gruppen-, das andere typ-spezifisch), die vielleicht Sonderleistungen der infizierten Zelle sind oder wahrscheinlicher unvollständiges Virus, bzw. Bausteine darstellen ${ }^{9}$. Bemerkenswert ist weiterhin, daß infi-

1 C. H. Andrewes, F. M. Burnet, J. F. Endres, S. Gard, G. K. Hirst, M. M. Kaplan u. V. M. Zhdanov, Virology 15, 52 [1961].

2 M. C. Davies, M. E. Englert, M. R. Stebbins u. V. J. Cabasso, Virology 15, 87 [1961].

3 J. W. Hartley u. W. P. Rowe, Virology 11, 645 [1960].

${ }^{4}$ I. MacPherson, P. Wildy, M. Stoker, u.. R W. Horne, Virology 13, 146 [1961].

5 R. W. Horne, S. Brenner, A. P. Waterson u. P. Wildy, J. molecular Biol. 1, 84 [1959].

6 M. A. Epstein u. A. K. Powell, Brit. J. exp. Pathol. 41, 559 [1960].

7 G. S. Boyer, C. Leuchtenberger u. H. S. Ginsberg, J. exp. Medicine 105, 195 [1957]. zierte Zellen, schon ehe infektiöse Teilchen synthetisiert sind, ein in $0,15-m \cdot-\mathrm{NaCl}$ DNS-Protein zu produzieren beginnen, das mit der Virussynthese parallel ansteigt und von der Zell-DNS verschieden ist ${ }^{10}$.

Im Versuchsprogramm ergab sich die Notwendigkeit, für das hier verwandte Zell-Virussystem erneut einen Plaquetest auszuarbeiten. Wie Bonifas, Schlesinger und Philipson ${ }^{11}$ gezeigt haben, bildet der hier beschriebene Typ 2 auf KB-Zellen plaques, und Typ 5 nach KJellen ${ }^{12}$ auf HeLa. Da offenbar jeder Zellstamm (vielleicht je nach PPLO-Befall) besondere Ansprüche stellt, mußte nochmals größere Mühe verwandt werden.

\section{Material und Methoden}

Virus: Das Adenovirus Typ 2 wurde uns freundlicherweise von Dr. Bonifas (St. Louis) überlassen. Es ist der gleiche Stamm, der auch auf KB-Zellen plaques gibt.

Zellkulturen: Das Adenovirus Typ 2 wurde in HeLa-Zellen vermehrt, die wir von den Herren Drs. Bögel und MAHnel (Bundesforschungsanstalt für Viruskrankheiten der Tiere, Tübingen) erhalten hatten. Die Zellen wurden in R o ux-Kolben (ca. $160 \mathrm{~cm}^{2}$ Fläche) oder in 2-l-Flaschen in Rollkultur gezüchtet (ca. $500 \mathrm{~cm}^{2}$ Fläche). Sie gedeihen gut in $\mathrm{E}$ a gle s

8 M. Green u. G. E. Daesch, Virology 13, 169 [1961].

9 L. Philipson, Virology 10, 459 [1960]; H. G. KLEMPERER u. H. G. Pereira, Virology 9, 536 [1959]; W. C. Wilcox u. H. S. Ginsberg, Proc. nat. Acad. Sci. USA 47, 512 [1961].

10 H. S. Ginsberg u. M. K. Dixon, J. exp. Medicine 109, 407 [1959]; 113, 283 [1961].

11 V. Bonifas u. R. W. Schlesinger, Federat. Proc. 18, 2196 [1959]; L. Philipson, Virology 15, 263 [1961].

12 L. KJELLEN, Virology 14, 234 [1961].

13 R. Dulbecco u. G. Freeman, Virology 8, 396 [1959].

14 P. I. Marcus, S. J. Cieciura u. T. T. Puck, J. exp. Medicine 104, 615 [1956]. 
Medium (Modifikation von Dulbecco ${ }^{13}$ ), dem zusätzlich Glycin, Asparaginsäure, Glutaminsäure, Serin, Hypoxanthin (Marcus und Mitarbb. ${ }^{14}$ ) und 10\% Kälberserum beigefügt sind. Vor der Infektion wurden die Zellschichten zweimal mit tris-gepufferter Salzlösung (Dulbecco ${ }^{13}$ ) gewaschen. Sie wurden mit $5 \mathrm{ml}$ entsprechend verdünnter infektiöser Lösung inoculiert und eine Stde. oder länger bei Zimmertemperatur zur Absorption stehen gelassen; anschließend wurden die Kulturen mit modifiziertem Eagles Medium übergossen und $3-4$ Tage im Brutschrank bei $37^{\circ} \mathrm{C}$ gehalten; dabei wurde mit soviel $\mathrm{CO}_{2}$ begast, daß das Kulturmedium neutral bis schwach sauer blieb. Die Virus-Konzentration zur Infektion war so gewählt worden, daß am 3 . oder 4 . Tag der cytopathogene Effekt sichtbar war und die Zellen leicht abgelöst und durch Zentrifugation geerntet werden konnten.

Virus-Gewinnung: Das Zellsediment von jeweils 15-30 Flaschen wurde in ca. $20 \mathrm{ml}$ VerseneSalzlösung aufgenommen und bis zum Gebrauch eingefroren. Nach dem Auftauen wurde 60 Sek. mit Ultraschall behandelt (MSE-Gerät bei $17 \mathrm{~A}$ in $50 \mathrm{ml}$ Zentrifugenbecher), so daß eine homogene milchige Suspension entstand. Für das Folgende wurde ein abgewandeltes Verfahren benutzt, wie es Crawford ${ }^{15}$ zur Isolierung von Rous-Sarcoma-Virus entwickelt hatte. Das Homogenat wurde zunächst 10 Sek. mit $20000 \mathrm{U} / \mathrm{min}$ im Rotor 30 der präparativen Spinco-Ultrazentrifuge gefahren, um die größeren Zellbestandteile zu sedimenren. Der trübe UUberstand wurde in Celluloidbecher für den Rotor SW 25 gefüllt und mit etwa $4 \mathrm{ml}$ CsClLösung $\varrho=1,55-1,60 \mathrm{~g} \cdot \mathrm{cm}^{-1}$ unterschichtet und 60 Sek. mit $25000 \mathrm{U} / \mathrm{min}$ zentrifugiert. Dabei sedimentiert eine schmale Bande in das dichte $\mathrm{CsCl}$ hinein und trennt sich von dem Rest der Zellbestandteile ab. Man läßt die Bande nach Anstechen des Bechers von unten abtropfen und verdünnt das Aufgefangene auf $4,5 \mathrm{ml}$ mit CsCl-Lösung in einem Celluloidbecher für den Rotor SW 39, so daß die Lösung endlich eine Dichte $\varrho=$ $1,355 \mathrm{~g} \cdot \mathrm{cm}^{-1}$ hat. In diesem Rotor wird $12-14$ Stdn. zentrifugiert. Dabei entstehen in der Regel 3 Banden oder Bandenbereiche, die durch ihre Lichtstreuung mit dem bloßen Auge sichtbar sind. Für die im folgenden berichteten Ergebnisse wurden die Bandenbereiche abgetrennt, die Zwischenschichten jedoch verworfen.

Cs Cl: Das hier verwandte $\mathrm{CsCl}$ stammt von der Firma Merck. Die Dichten der Lösungen wurden aus ihren Brechungsindices mit Hilfe einer Eichkurve ermittelt. Die Werte der Eichkurve sind pyknometrisch gemessen worden (Abb. 1).

Elektronenmikroskopische Aufnahm en : Für elektronenmikroskopische Präparate wurde Virussuspension auf Kollodiummembran aufgetragen. Nach dreimaligem Waschen mit dest. Wasser wurde mit PtRh bedampft. Diese Aufnahmen wurden am EM 8AEG-Zeiss-Gerät gemacht. Für die stärkeren Vergrößerungen wurde das negative-staining-Verfahren angewandt ${ }^{15}$; statt auf Kohlenmembranen wurde auf $1,0 \%$

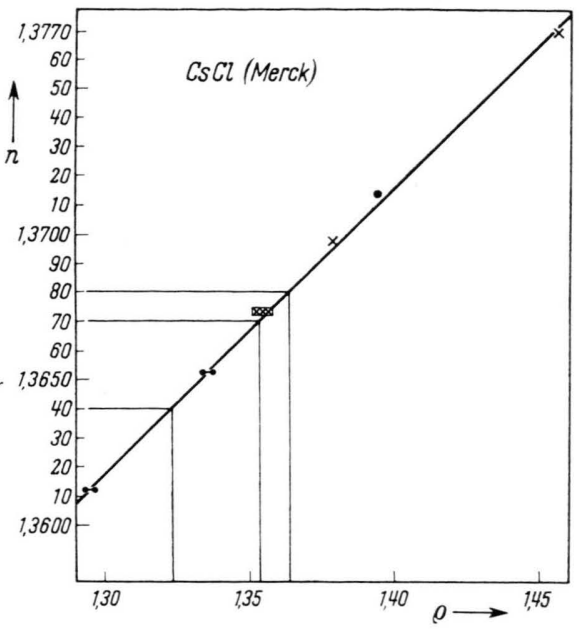

Abb. 1. Eichkurve. CsCl (Merck)-Lösung. Abhängigkeit der Dichte von dem Brechungsindex $(n)$.

Formvar aufgesprüht. Die so angefertigten Objektträger wurden mit dem Siemens-Elmiskop durchgesehen.

P l a que-Test : Der Plaque-Test wurde in Petrischalen von $5 \mathrm{~cm}$ Durchmesser angesetzt. Nach der Inoculation wurde mit $10 \mathrm{ml}$ Nähragar folgender $\mathrm{Zu}$ sammensetzung übergossen:

50\% 0,9-proz. Agar (Difco),

$45 \%$ 2 E a g les Medium (=doppelte Konzentration aller Bestandteile),

5\% embryonales Kälberserum (Colorado Serum Co.). Am siebenten Tage darauf wurden nochmals $5 \mathrm{ml}$ desselben Agarmedium dazugegeben, das außerdem Neutralrot enthielt. Die Plaques wurden am 10. bzw.

12. Tage nach der Inoculation gezählt. Das embryonale Kälberserum erwies sich für den Test als besonders geeignet und ergibt reproduzierbare Ergebnisse.

\section{Ergebnisse}

Aus Homogenaten von HeLa-Zellen, die mit Adenovirus Typ 2 infiziert worden waren, konnten nach dem beschriebenen Verfahren 3 Bandenbereiche isoliert werden, die (sofern nicht ausdrücklich anders angegeben) ohne weitere Reinigung zu den folgenden Untersuchungen eingesetzt wurden (Abb. 2). Normale HeLa-Zellen enthalten kein Material, das nach Aufarbeitung solche Banden ergibt.

Der schwere Bandenbereich "B 1", der im CsClGradienten ein bis drei Banden dicht nebeneinander sichtbar macht (Abb. 3), enthält als Hauptkomponente Partikel mit einer Sedimentationskonstante $s 20 \mathrm{w}=779,8 \mathrm{~S}$. Diese Banden liegen im CsCl-

15 L. V. Crawford, Virology 12, 143 [1960]. 

Trennung der Bandenbereiche B 1, B 2, B 3 in CsCl-Gradienten, Präp. Spinco-Ultrazentrifuge, Rotor SW 39, $30000 \mathrm{U} /$ min, 12 Stdn. Laufzeit, $\mathrm{CsCl}=1.352$.
Abb. 2. Adenovirus Typ 2,

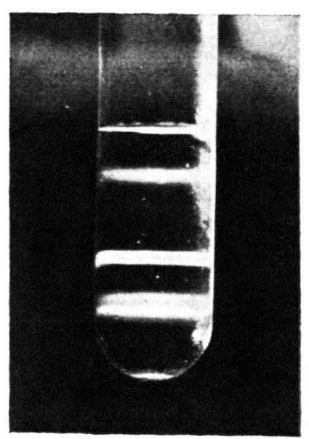

Gradienten bei einer Dichte um $\varrho=1,365$. Die Bande „B 2“ ist einheitlich (Abb.4) und bildet den Hauptanteil bei guten Präparaten, sie hat eine Dichte

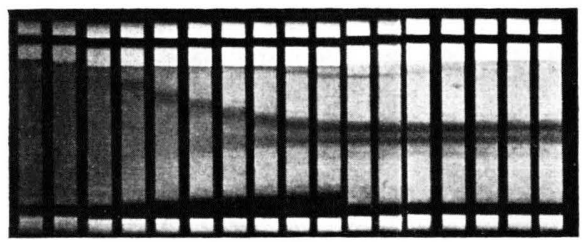

Abb. 3. Adenovirus Typ 2, Bandenbereich B 1 enthält 3 Einzelbanden. CsCl-Gradienten-Zentrifugation. Analytische Spinco-Ultrazentrifuge, $\mathrm{CsCl}=1,365 \mathrm{~g} \cdot \mathrm{cm}^{-1}$.

im $\mathrm{CsCl}$ von $\varrho=1,355$ und enthält die eigentlichen und infektiösen Viruspartikel. Bei einem Titer von ca. $10^{7} \mathrm{pfu}^{*} / \mathrm{ml}$ der Ausgangslösung wurden wiedergefunden in:

B 1 schwere Banden

B 2 Virus

Zwischenschicht $\mathrm{n}=1,3650$

B 3 leichte Banden $1 \cdot 10^{8} \mathrm{pfu} / \mathrm{ml}$
$1 \cdot 10^{12} \mathrm{pfu} / \mathrm{ml}$
$1 \cdot 10^{9} \mathrm{pfu} / \mathrm{ml}$
$4 \cdot 10^{8} \mathrm{pfu} / \mathrm{ml}$

Bande 2 enthält somit mehr als $99 \%$ des infektiösen Virus. Sie sedimentiert unter den gegebenen Bedingungen mit einer $s 20 \mathrm{w}=618,5 \mathrm{~S}$. Im elektronenmikroskopischen Bild zeigt diese Fraktion bei einigen Präparaten so gut wie nur eine Art Partikel mit einem Durchmesser von $70 \mathrm{~m} \mu$. Bei einigen Aufarbeitungen (Abb. $\left.5^{*}\right)$ sind die Partikel offenbar im Begriff zu zerfallen und erscheinen daher flacher und von größerem Durchmesser. Besonders interessant waren zwei Versuche, die die in Abb. 6 dar-

$*$ pfu $=$ plaque forming units.

15a S. Dales, J. Cell Biology 13, 303 [1962].

16 G. Schramm u. H. Dannenberg, Chem. Ber. 77, 53 [1944].

17 K. KECK, Arch. Biochem. Biophysics 63, 446 [1956].

18 R. B. Hurlbert, H. Schmitz, A. F. Brumm u. V. R. Potter, J. biol. Chemistry 209, 23 [1954].

* Anm. b. d. Korr.: Dales ${ }^{15}$ a weist darauf hin, daß die Capsomeren möglicherweise nicht kuglig sind, wie bei dem von Horse u. Mitarbb. ${ }^{5}$ gebauten Modell (Plate gestellten Verhältnisse zeigen. Neben Partikeln von hexagonalem Umriß, die dem intakten Virus entsprechen könnten, liegen flache schattenlose kleinere Gebilde, dazu ist der Untergrund von sehr kleinem, kugeligem Material übersät. Hierfür ist (da es sich hier um ein zweites Mal in CsCl-Gradienten gereinigtes Material handelt) die Deutung wahrscheinlich, daß beim Waschen der elektronenmikroskopischen Präparate mit dest. Wasser unter noch nicht genau erkannten Bedingungen, das Virus in seine Untereinheiten zerfällt.

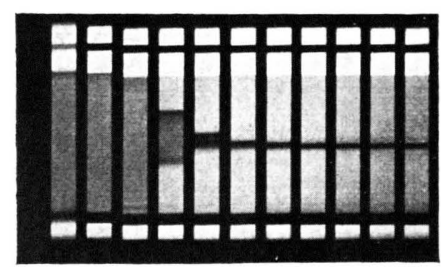

Abb. 4. Adenovirus Typ 2. Die einheitliche Virus-Bande B 2. CsCl-Gradienten-Zentrifugation. Analytische Spinco-Ultrazentrifuge, $\mathrm{CsCl}=1,35 \mathrm{~g} \cdot \mathrm{cm}^{-1}$.

Durch Anwendung des negative-staining-Verfahrens konnte weiterhin nachgewiesen werden, daß entsprechend den Befunden von Horne und Mitarbb. ${ }^{5}$ die Partikel Polyeder sind, und zwar Icosaeder mit einer Kantenlänge von 6 Untereinheiten, wie man bei x (Abb. 7) abzählen kann *. Das Absorptionsspektrum im UV zeigt nach Korrektur für die Lichtstreuung der Partikel ${ }^{16}$ ein Maximum bei $259 \mathrm{~m} \mu$.

\section{Der Quotient $\frac{\text { OD } 260 \text { Absorption }}{\text { OD } 280 \text { Absorption }}$ beträgt 1,308.}

In $\mathrm{B} 2$ ist DNS nachweisbar ${ }^{17}$, dagegen keine RNS (Erfassungsgrenze 0,14\%) ${ }^{18}$. Der Bandenbereich B 3 enthält meist 2 deutliche Banden, die bei einer Dichte des CsCl von $\varrho=1,31-1,33 \mathrm{~g} \cdot \mathrm{cm}^{-1}$ liegen. Die Schwere dieser Banden enthält Partikel mit einer Sedimentationskonstanten $s 20 \mathrm{w}=558 \mathrm{~S}$.

Im Elektronenmikroskop erscheinen diese Partikel mit einem etwas größeren Durchmesser von ca. $85-95 \mathrm{~m} \mu$, sind aber flacher als die Partikel von B 2 (Abb. 8). Negative-staining-Präparationen zei-

II b), sondern eher kurze Hohlzylinder, ähnlich den Capsomeren des Herpesvirus. Abb. 7 zeigt z. B. bei x solche Formen. In der gleichen Abb. sowie in Abb. 9 sind auch die spitzen Fortsätze (= spikes) sichtbar, die nach Dales vielleicht bei der Absorption eine Rolle spielen. Bei der Schwierigkeit der Deutung elektronenmikroskopischer Bilder soll daher nur anhangsweise darauf hingewiesen werden.

* Abb. 5-9 s. Tafel S. 546 a, b und c. 
O, 1

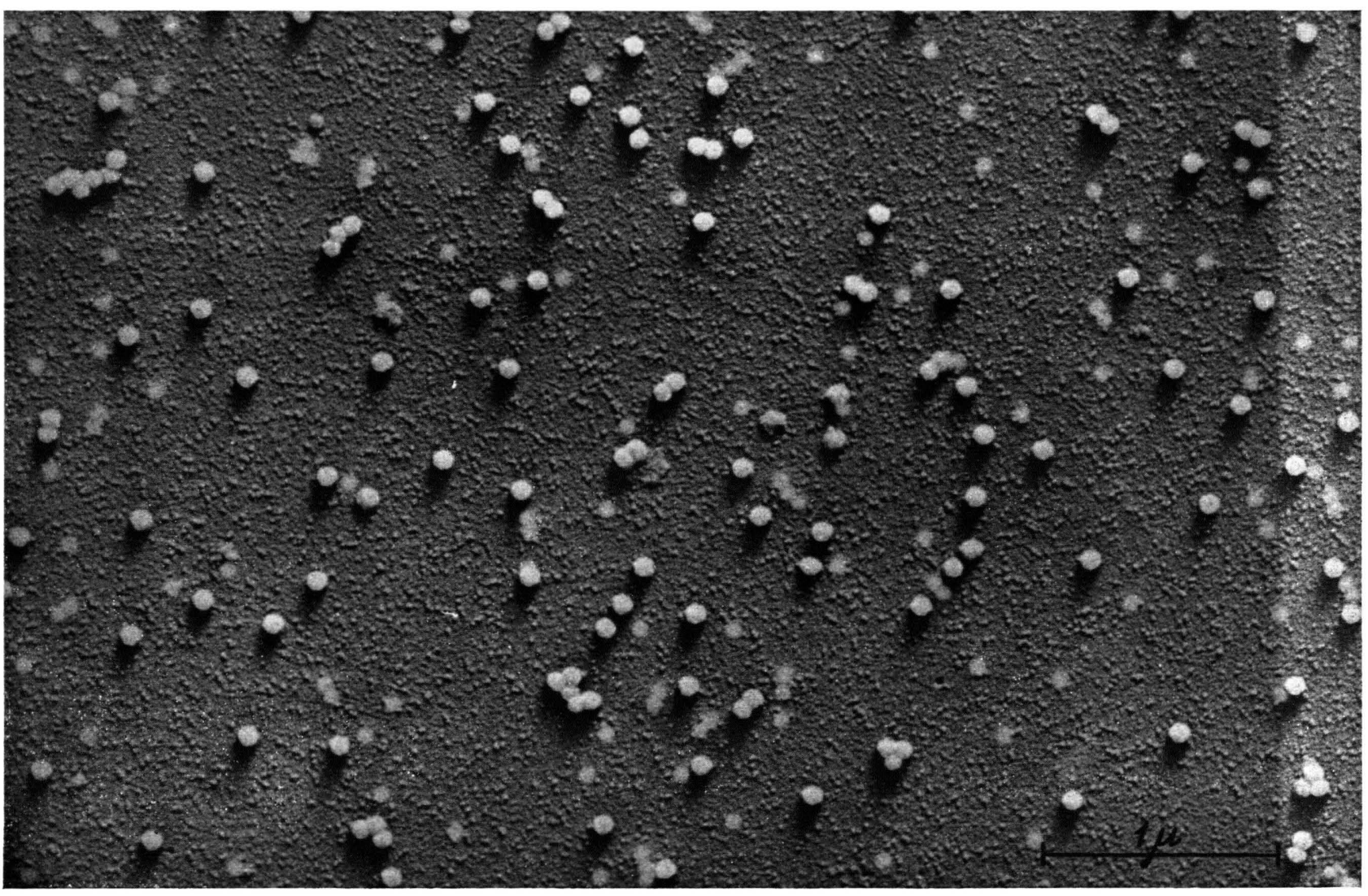


Abb. 7

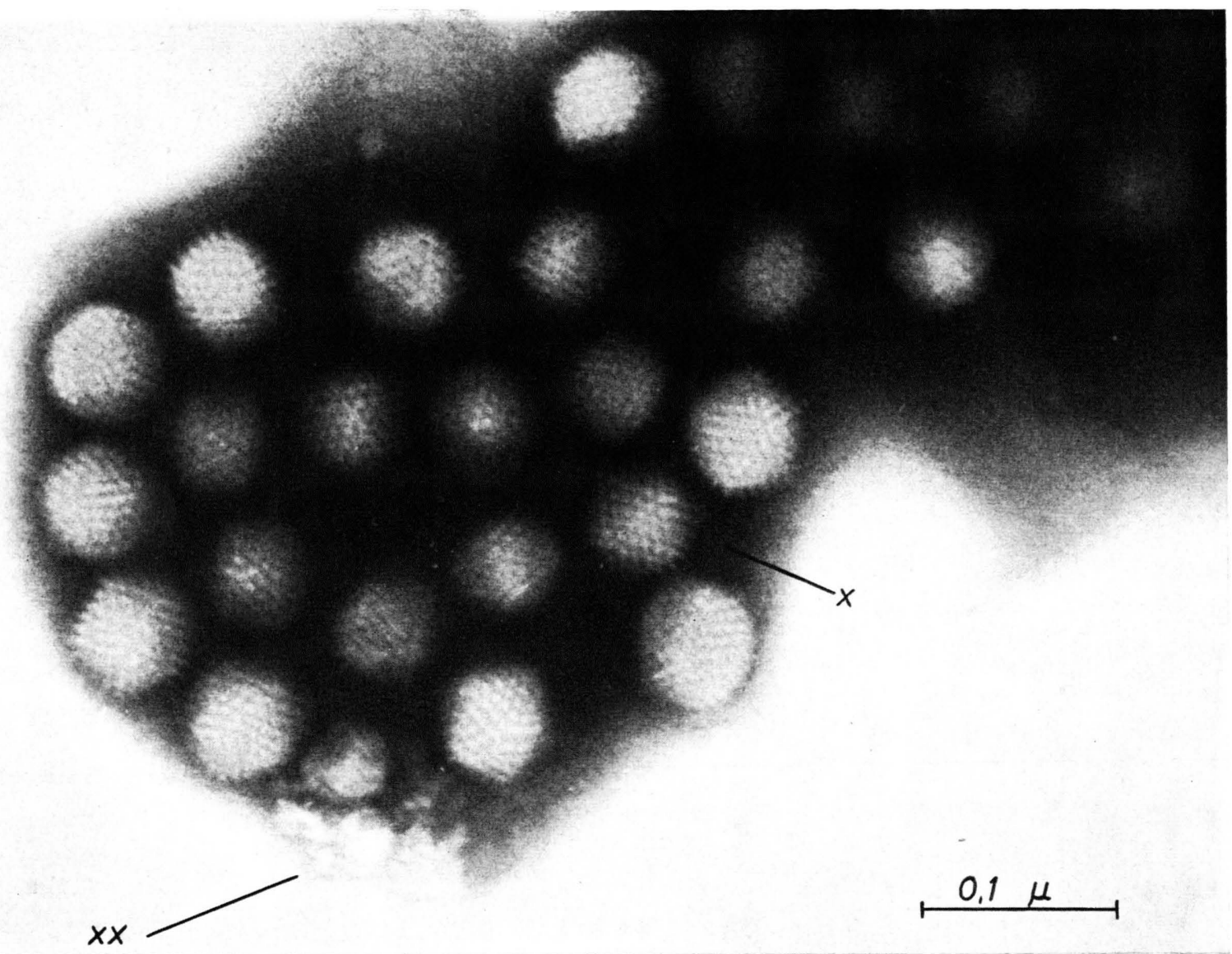

Abb. 8

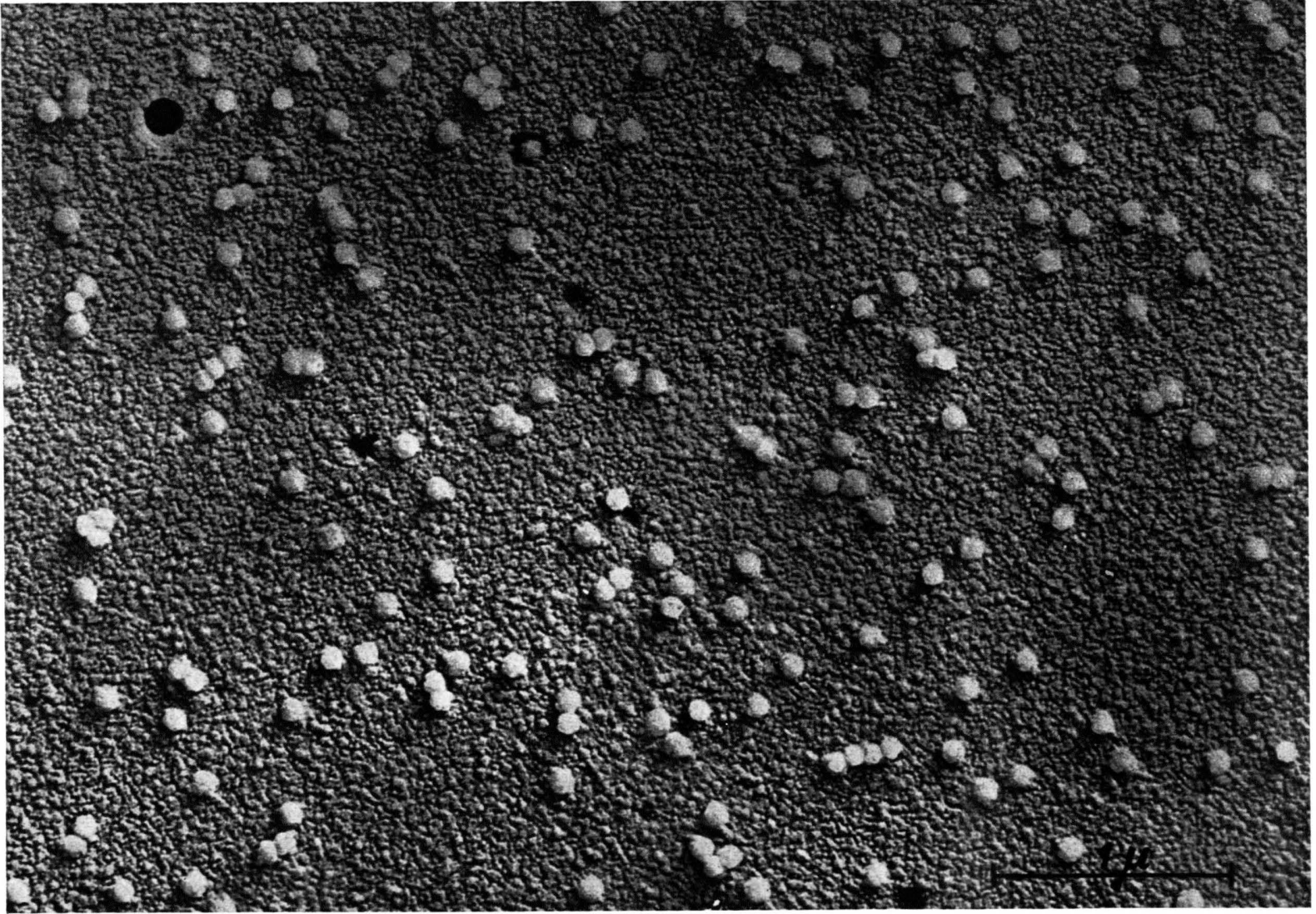


Abb. 5. Adenovirus Typ 2, Viruspartikel der B 2, im Begriff zu zerfallen. Präparat auf Kollodium aufgetragen, mit dest. Wasser gewaschen, bedampft mit PtRh, Vergr. 30000 -fach. Man beachte, daß der Untergrund so gut wie frei von feinem Material ist.

Abb. 6. Adenovirus Typ 2, Partikel der „Virus“-Bande B 2. Elektronenmikrosk. Präparation wie Abb. 5. Man beachte außer Partikeln mit hexagonalem Umriß die flachen elektronendichten Scheiben und die feinen Granula.
Abb. 7. Adenovirus Typ 2,Viruspartikel der B 2. Negativestaining-Präparation (s. Text). Aufnahme: Frank mit Siemens-Elmiskop, Vergr. 240 000-fach. Bei x ist eine Kante der Icosaeder mit 6 Capsomeren sichtbar, bei xx liegt ein offenbar zerfallenes Partikel.

Abb. 8. Adenovirus Typ 2, Viruspartikel der B 3. Präparation wie Abb. 5.
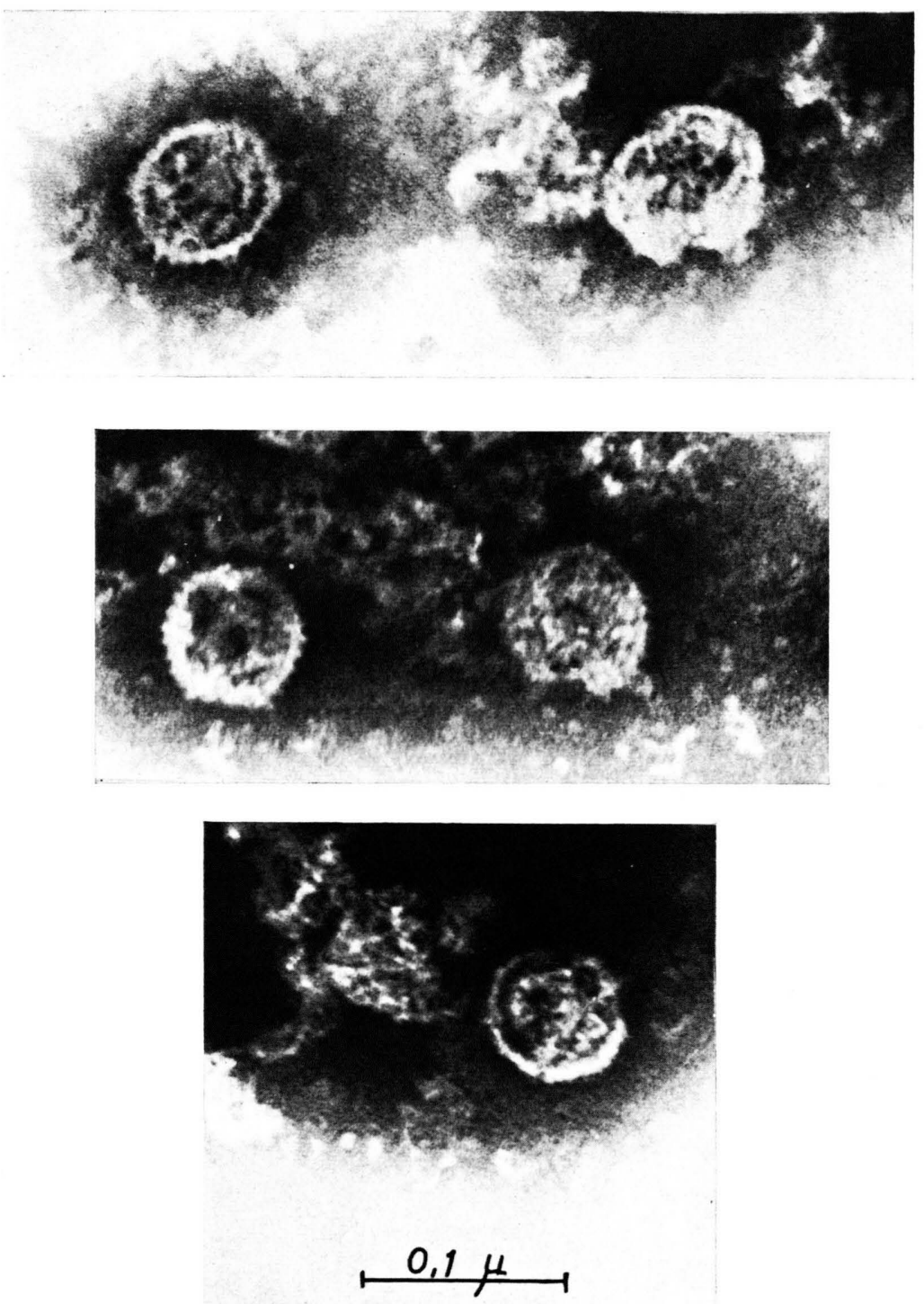

Abb. 9. Adenovirus Typ 2, Partikel aus dem Bandenbereich

B 3. Negative-staining-Präparation (s. Text). Aufnahme: mit Siemens-Elmiskop, Vergr. 240000 -fach. 

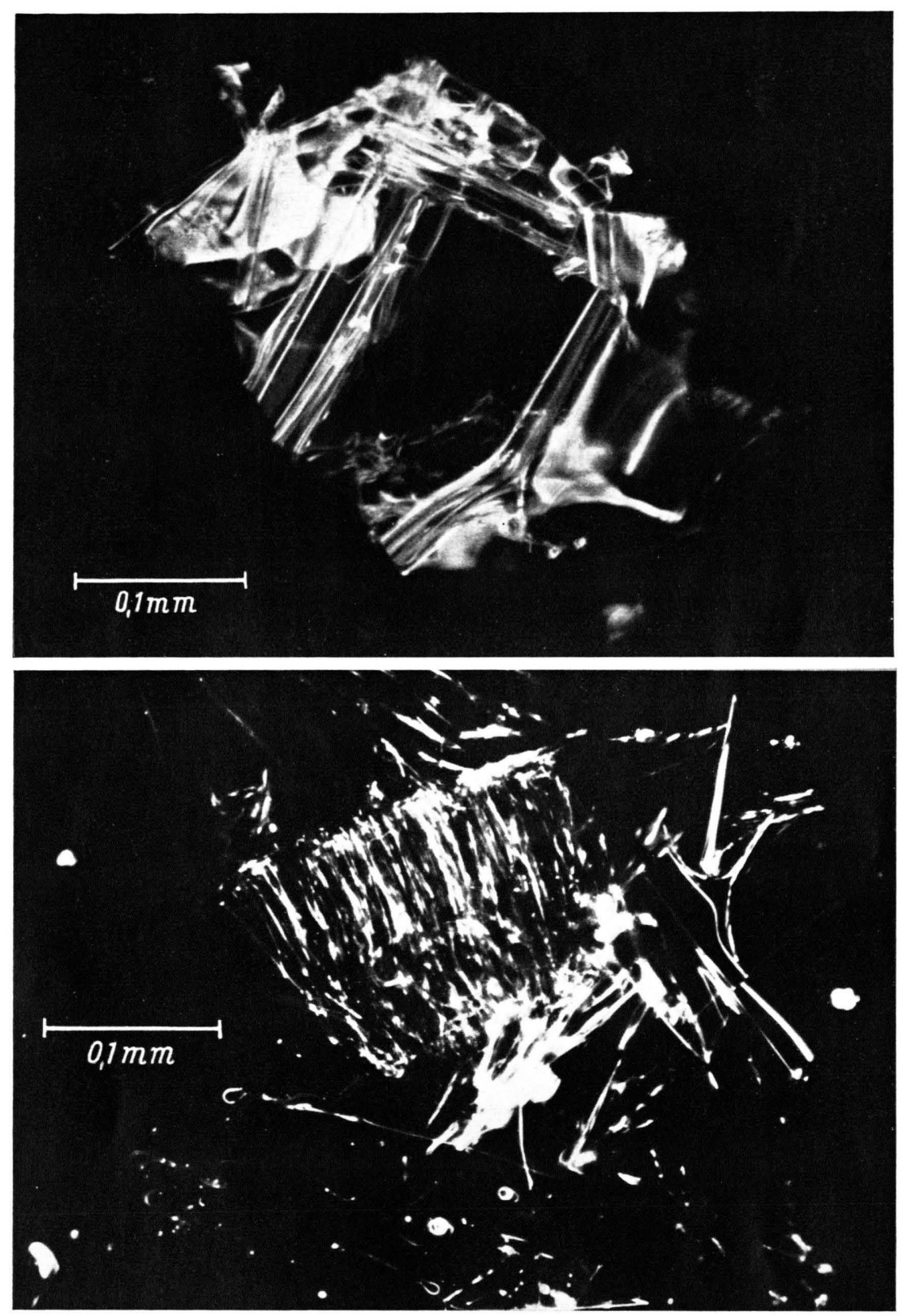

Abb. 8. Mikrophotographie einer aus dem Sol ausgefrorenen Kieselsäureschuppe in Aufsicht. Maßstab eingezeichnet.
Abb. 9. Mikrophotographie einer aus dem Sol ausgefrorenen Kieselsäureschuppe in Seitensicht. Maßstab eingezeichnet.

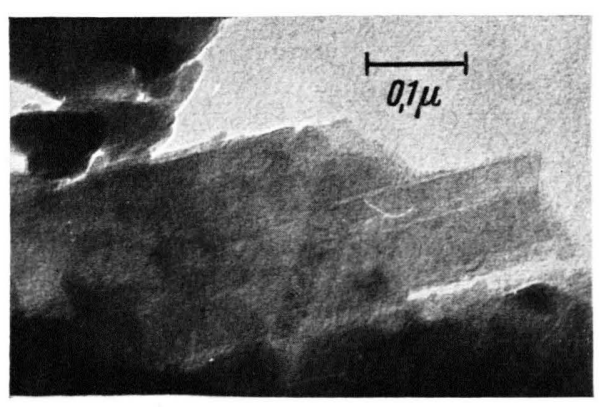

Abb. 10. Aus dem Sol ausgefrorene Kieselsäureschuppen; Gesamtvergrößerung 100 000-fach (Maßstab eingezeichnet). Aufnahme W. Vogell.

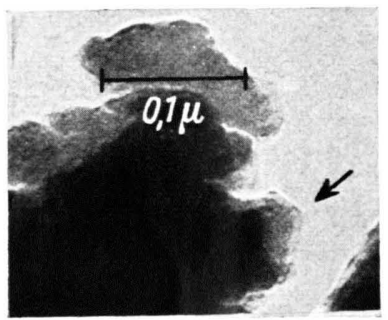

Abb. 11. Aus dem Sol ausgefrorene Kieselsäureschuppen; Gesamtvergrößerung 100 000-fach (Maßstab eingezeichnet.) Aufnahme W. Vogell. 
gen, daß diese Fraktion aus leeren Hüllen besteht, die z. T. im Zerfall begriffen sind (Abb. 9).

\section{Besprechung der Ergebnisse}

Bei der hier verwandten Methode, Virus in CsClLösungen hoher Dichte zu zentrifugieren, gelingt es innerhalb von $12 \mathrm{Stdn}$. Mengen von etwa $5 \mathrm{mg}$ Virus in einer schmalen Bande zu konzentrieren, ohne sie zu stark zusammenzupressen. Vorversuche hatten ergeben, daß die Ausbeute von Virus, das aus verdünnten Lösungen auf den Boden des Röhrchens zentrifugiert wurde, sehr gering ist. Während des 12-stdg. Laufes bei $30000 \mathrm{U} / \mathrm{min}$ ist der Gradient noch im Entstehen. Das bedeutet, daß vorwiegend die größeren Partikel, jedoch nicht die Spuren verunreinigender Proteine in die Gleichgewichtszone ihrer Dichte $\varrho=1,3 \mathrm{~g} \cdot \mathrm{cm}^{-1}$ gelangt sind. Daher sind die hier angegebenen Sedimentationskonstanten, die aus einer und derselben Aufarbeitung stammen, zunächst nur untereinander vergleichbar. Frühere Sedimentations-Bestimmungen an Typ 4 ergaben Werte zwischen $539 \mathrm{~S}$ und $680 \mathrm{~S}$ für die infektiöse Komponente ${ }^{19}$, was unseren Messungen nahe kommt.

Die elektronenmikroskopischen Untersuchungen der Bande 2 zeigen Viruspartikel, die denen der Aufnahmen von Horne und Mitarbb. gleichen. So wie bei Typ 5 besteht auch bei Typ 2 das Capsid aus 252 Capsomeren. Zerfallende Virusteilchen scheinen aus einer im Inneren sich befindlichen $\mathrm{Nu}$ cleinsäure bzw. Nucleoprotein-,Kern“ zu bestehen, der in Abb. 6 als schattenlose Scheibe freigelegt ist; die dazu gehörigen kleinen Protein-Untereinheiten, die Capsomeren, liegen mehr oder weniger aggregiert über das Feld verteilt. Dieser Nucleoprotein„Kern“ dürfte den Partikeln des Bandenbereiches B 3 ganz fehlen oder reduziert sein, woraus deren geringe Dichte bzw. die geringere Sedimentationskonstante verständlich wird. Auch HonNe und Mitarbb. zeigen in ihrer Abb. "Plate I (a) " in der Ecke links oben ein solches "leeres" Partikel des Adenovirus Typ 5 neben 3 „vollständigen“. Da das Material der drei Bandenbereiche nur aus infizierten, nicht aber aus normalen Hela-Zellen gewonnen werden konnte, so darf man wohl die leeren Hüllen

19 M. R. Hilleman, A. J. Tousimis u. J. H. Werner, Proc. Soc. exp. Biol. Med. 89, 587 [1955].

20 R. E. F. Matthews, Virology 12, 521 [1960].

20 a S. Brenner u. R. W. Horne, Biochim. biophysica Acta [Amsterdam] 34, 103 [1959]. in B 3 mit einiger Wahrscheinlichkeit als Viruscapside ansprechen, wenn auch der serologische Nachweis noch aussteht.

Der Vergleich der Partikel aus den Banden B 2 und B 3 würde den Schluß nahelegen, daß in B 1 auf Grund ihrer größeren Dichte und Sedimentationskonstante dann reichlicher DNS enthalten wäre. Elektronenmikroskopische Aufnahmen von negative-staining-Präparaten von B 1-Partikeln sind bisher nicht gelungen.

Matrhews ${ }^{20}$ hat auf ähnliche Weise beim turnip yellow mosaic virus (TY) 5 Fraktionen Virus- und virusverwandtes Material mit Hilfe der CsCl-Gradienten-Zentrifugation erhalten, die sich in ihrem Nucleinsäure-Gehalt unterscheiden und zwar mit einem Spielraum von 6,0-39,0\% RNS im Partikel, außer der „Top"-Komponente, die nach Aufnahmen von Brenner und Horne ${ }^{20 a}$ sowieso leere Hüllen und somit keine $(=0,9 \%)$ RNS enthält. Die Fraktion (B 3) der leeren Hüllen des Adenovirus enthält weniger als $0,1 \%$ der Infektiosität. Solche nichtinfektiöse Hüllen lassen sich sogar experimentell beim Pseudorabiesvirus durch Anwendung von 5-Fluouracil erzeugen ${ }^{21}$. Bei der Durchsicht der elektronenmikroskopischen Arbeiten über sphärische Viren findet man, daß solche defekte bzw. unvollständige Viruspartikel, nämlich Capside, denen der Nucleoprotein-„Kern“ fehlt, weit verbreitet sind.

Diese Capside scheinen recht stabil zu sein, da sie die verschiedenartigsten Reinigungsverfahren überstehen und meist mit dem morphologisch intakten Virus vergesellschaftet bleiben. Die Trennung gelingt wie im Falle von TY, Reovirus ${ }^{22}$ und Adenovirus durch Dichtezentrifugation; bei Poliovirus konnten die leeren Capside mit Hilfe von Antisera von den vollständigen Partikeln getrennt werden ${ }^{23}$.

Über die physikalischen, chemischen und serologischen Eigenschaften der oben beschriebenen, in den einzelnen Banden gefundenen Partikel des Adenovirus, soll später berichtet werden.

Herrn Dr. H. Frank vom Max-Planck-Institut für Biologie, Abt. WeIDEL, danke ich besonders für die Aufnahmen am Siemens-Elmiskop (Abb. 7 und 9). Herr Kraus, Abt. Schäfer, beriet mich bei der Roll. kultur. Herrn Dr. Bonifas und Herrn Professor SchlesINGER, St. Louis, sei für die Überlassung ihres Virusstammes und mancherlei Ratschläge ebenso gedankt.

21 M. Reissig u. A. S. Kaplan, Virology 16, 1 [1962].

22 J. S. Rhim, K. O. Smith u. J. L. Melnick, Virology 15, 428 [1961].

23 K. Hummeler u. Mitarbeiter, Virology 16, 84 [1962]. 